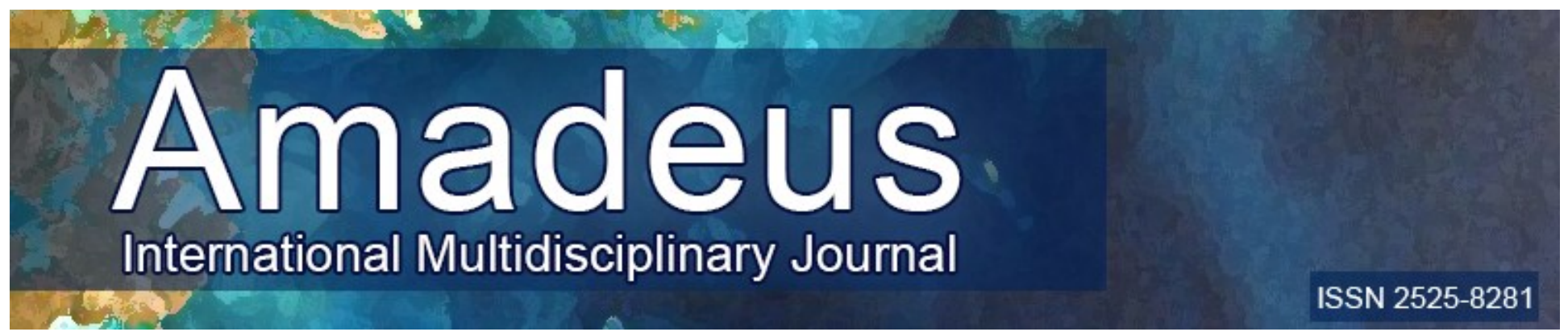

DOI: 10.14295/AIMJ.V6I11.172

\title{
Historical approach on the creation of the Femicide Law in Brazil
}

\author{
Athena de Albuquerque Farias ${ }^{1}$
}

\begin{abstract}
Historically, Brazilian society has incorporated the dictates of a patriarchal structure. This patriarchal structure is essentially sexist, where male figures stand out and carry a feeling of domination and power over women. This study aims to analyze the historical and sociocultural aspects that led Brazil to edit the Feminicide Law. In this fight against violence against women, the feminist movements have been one of the biggest collaborators. The creation of the penal type of femicide is, therefore, considered a political and academic landmark for feminism, as it gave visibility to the growing deaths of females due to gender. The enactment of the law aimed to reduce crimes against women based on gender, with the modification of the judgment and increase of penalties for this type of criminal, with the intention of inhibiting new criminal practices, as well as creating awareness in society about the lethal death of women and how it affects society.
\end{abstract}

Keywords: femicide, gender inequality, patriarchal society.

Resumo: Historicamente, a sociedade brasileira incorporou os ditames de uma estrutura patriarcal. Essa estrutura patriarcal é essencialmente sexista, onde as figuras masculinas se destacam e carregam um sentimento de dominação e poderio sobre as mulheres. O presente estudo visa analisar os aspectos históricos e socioculturais que levaram o Brasil a editar a Lei do Feminicídio. Nessa luta contra a violência contra as mulheres, os movimentos feministas têm sido um dos maiores colaboradores. A criação do tipo penal do feminicídio é, portanto, considerado um marco político e acadêmico para o feminismo, pois conferiu visibilidade para as crescentes mortes de pessoas do sexo feminino em razão do gênero. A edição da lei teve o objetivo de reduzir os crimes contra as mulheres em razão do gênero, com a modificação do julgamento e aumento das penas para este tipo penal, com intenção de inibir novas práticas delituosas, assim como de criar consciência na sociedade sobre a morte letal de mulheres e como isso afeta a sociedade.

Palavras-chave: feminicídio, desigualdade de gênero, sociedade patriarcal. 


\section{Introdução}

Historicamente, a sociedade brasileira incorporou os ditames de uma estrutura patriarcal, que se desenvolveu instrumentalizada por verticalização ideias, conceitos e costumes, nos quais o gênero masculino se sobrepõe sobre o feminino. Essa estrutura patriarcal é essencialmente sexista, onde as figuras masculinas se destacam e carregam um sentimento de dominação e poderio sobre as mulheres.

É de fácil percepção que, até atualmente, ainda existe essa necessidade de dominação e submissão do sexo feminino. No entanto, igualmente é possível verificar a ocorrência de avanços nas relações sociais, impulsionado por movimentos feministas, que visam lutar contra essa desigualdade de gêneros.

A desigualdade existente entre os gêneros é o principal motivo desencadeador da violência contra as mulheres, devido ao sentimento de superioridade e de dominação que os homens carregam. Esse tipo de crime tem crescido nos últimos tempos de forma considerável, motivo pelo qual ele passou a ter mais visibilidade.

Atualmente o Brasil ocupa a quinta posição no ranking dos países com maior número de casos de feminicídio. Essa situação é tão alarmante, que se torna necessário problematizar a situação, entendendo o porquê este crime ainda é frequentemente cometido e em proporções cada vez maiores.

Acredita-se que os moldes europeus enraizados no país na época colonial, implantaram padrões de gênero na sociedade, que legitimam uma aparência de superioridade do sexo masculino. Com isso, tem-se uma estrutura social essencialmente machista, que coloca as mulheres em situação de vulnerabilidade, com maiores riscos de ser vítima de violência.

A mais grave expressão da violência contra as mulheres é óbito da vítima. Em relação ao feminicídio, esse a morte ocorre em razão do gênero, ou seja, pelo simples fato da vítima ser do sexo feminino. A partir disto, torna-se relevante compreender a demanda que ensejou a implementação da Lei do Feminicídio, a fim de entender o que tornou este crime tão visível a ponto de se tornar tipo penal.

A partir desta perspectiva, o presente estudo tem fulcro de discorrer acerca do percurso histórico da inserção do feminicídio como circunstância qualificadora do 
homicídio, visando desenvolver uma reflexão a respeito da temática que colaborem para o entendimento da questão, bem como para seu combate e enfrentamento.

O presente estudo visa analisar os aspectos históricos e socioculturais que levaram o Brasil a editar a Lei do Feminicídio

\section{O surgimento do termo "feminicídio" e seu significado}

O termo "feminicídio" foi usado pela primeira vez em 1976 por Diana Russel, em depoimento realizado no Tribunal Internacional sobre Crimes Contra as Mulheres. No entanto, a expressão apenas recebeu uma definição em 1990, conferida por Diana Russel em conjunto com Jane Caputi, que definiram feminicídio como um genocídio de pessoas do sexo feminino por razões de gênero, motivado pelo ódio, menosprezo, discriminação, dominação e sentimento de posse sobre as mulheres (RUSSEL; CAPUTI, 1990). Conforme descrito por Pasinato:

De acordo com a literatura consultada, Russel e Radford utilizaram a expressão para designar os assassinatos de mulheres que teriam sido provocados pelo fato de serem mulheres (...) outro característica que define feminicídio é não ser um fato isolado na vida das mulheres vitimizadas, mas apresentar-se como um ponto final em um continuum de terror, que inclui abusos verbais e físicos e uma extensa gama de manifestações de violência e privações a que as mulheres são submetidas ao longo de suas vidas (PASINATO, 2011, p. 224).

Nesse diapasão, o feminicídio é considerado como sendo a etapa final de uma sequência de atos de violência contra a mulher, cujo fundamento repousa em razões misóginas, bem como em uma cultura essencialmente sexista (RODRIGUES; MOROTTI, 2017).

Em 2006, Marcela y de los Ríos Lagarde (2006) traz à tona o elemento impunidade relacionado ao delito, que decorre da omissão e negligência do Estado no combater e enfrentamento dos mais diversos tipos de violência contra as mulheres, dentro os quais está o feminicídio. Com isso, incorpora ao termo o dever do Estado de proteger as vítimas, com a edição de leis e políticas públicas que assegurem a segurança delas, sob pena de ser consideração autor do crime por conta da inércia (RODRIGUES; MOROTTI, 2017). No entendimento de Marcela Lagarde (apud ESPÓSITO, 2011): 
A categoria feminicídio é parte da base teórica feminista. Desenvolvi-a a partir da obra de Diana Russell e Jill Radford, apresentada em seu texto Femicide. The politics of woman killing (1992). A tradução de é femicídio. Mudei de para o feminicídio, porque em espanhol é termo homólogo e só significa homicídio e assassinato de mulheres. As referidas autoras definem o feminicídio como um crime de ódio contra as mulheres, como todas as formas de violência que por vezes terminam em assassinato e até mesmo suicídio. Identifico um problema mais por tais crimes se estenderem no tempo: a ausência ou fraqueza do Estado de Direito, na qual se reproduzem a violência ilimitada e assassinatos sem castigo. Então, para diferenciar os termos, preferi o termo feminicídio e assim designar o conjunto de crimes contra a humanidade que consistem em atos criminosos, sequestros e desaparecimentos de meninas e mulheres em um contexto de colapso institucional. É uma fratura do Estado de direito que favorece a impunidade. Por isso eu digo que feminicídio é um crime de Estado. Deve ser esclarecido que existe feminicídio em condições de guerra e paz.

Atualmente, entende-se que feminicídio ${ }^{2}$ se trata “(...) de uma modalidade de homicídio qualificado criada pela Lei 13.104, de 9 de março de 2015. O feminicídio ocorre quando o crime envolve violência doméstica e familiar; ou menosprezo ou discriminação à condição de mulher” (LOUREIRO, 2017).

Urge comentar entendimento de Damásio de Jesus (2015), no qual o autor salienta a importância social ${ }^{3}$ do conceito de feminicídio, pois ele revela a desigualdade de gênero que ainda é muito presente na sociedade, uma vez que tenta justificar o delito com situações em que a mulher foge dos papéis de gênero ditados culturalmente.

Segundo o mesmo autor, o crime de feminicídio se divide em íntimo, não íntimo e por conexão. O primeiro ocorre quando a mulher mantinha ou já manteve relação íntima ou familiar com o agressor, podendo envolver cônjuges/excônjuge, companheiro/ex-companheiro, parceiro/ex-parceiro, amantes, namorado/exnamorado, padrasto, pai, primo, irmão etc. Este é o que ocorre com mais frequência, uma vez que ele ocorre no âmbito familiar (JESUS, 2015, ROMERO, 2014 apud OLIVEIRA et al, 2015).

O feminicídio não íntimo é quando o delito é causado por sujeito que não possui qualquer ligação com a vítima. Neste tipo, incluem-se o homicídio provocada por

\footnotetext{
${ }^{2}$ Nesse mesmo sentido: "As Nações Unidas definem este termo [feminicídio] como «o assassinato de mulheres por serem-no». É uma das mais sangrentas e visíveis [formas de violência]. Geral mente é precedido por violência sexual e outros atos que ameaçam a dignidade das mulheres, tanto por agressores conhecidos como desconhecidos" (Agatón 2013, apud SOUSA, 2016).

${ }^{3} \mathrm{O}$ conceito de feminicídio é útil porque nos indica o caráter social e generalizado da violência baseada na inequidade de gênero e nos impede de elaborar teses que tendem a culpar as vítimas e a representar os agressores como "loucos", "fora do controle", ou a conceber essas mortes como crimes passionais. Apesar disso, essas concepções ocultam e negam a verdadeira dimensão do problema. Assim, o conceito de feminicídio ajuda a desarticular os argumentos de que a violência baseada na inequidade de gênero é um assunto privado e mostra seu caráter social, produto das relações de poder entre homens e mulheres. (JESUS, 2015, p. 13).
} 
clientes da prostituição, amigos, vizinhos e até desconhecidos, bem como aqueles decorridos do tráfico de mulheres (FLORES, 2012 apud GEBRIM \& BORGES, 2014).

Por último, o feminicídio por conexão abarca os delitos que o homem tem o objetivo de matar outra mulher, mas assassina vítima que não era alvo, devido ao fato de ela estar na hora errada e no local errado.

Conforme pode se verificar, o termo que atualmente é utilizado para se referir ao crime de feminicídio, teve origem em um conceito que se pautava do genocídio de mulheres, como forma de nomear esse tipo de violência contra o sexo feminino. Atualmente, ele é especificamente utilizado para se referir aos homicídios de mulheres em razão do gênero, podendo ser dividido em subtipos a depender da relação que a vítima tinha com o agressor.

\section{Influência do feminismo}

$\mathrm{Na}$ análise do feminicídio, é relevante estudar a influência do feminismo para a edição da lei, pois ele atuou fortemente contra a imposição social relacionado ao papel de submissão que a mulher deveria ocupar na sociedade machista.

Estudiosos comentam que houve a criação de um quadro de dominação patriarcal, no qual foi realizada a diferenciação de gêneros com base em uma hierarquia de valores e direitos relacionados a homens e mulheres. Como resultado, obteve-se uma apropriação do homem sobre a vida da mulher (SOUSA, 2016), colocada como submissa.

Essa submissão existe entre a mulher e os demais patriarcas, tais como seu marido, pai, sogros, avôs etc.; e acabou desencadeando um processo de submissão e sujeição das pessoas do sexo feminino ao próprio aparelho estatal (SILVA; SEABRA; SOARES JÚNIOR, 2016, p. 302), que sempre a colocou em uma posição de inferioridade.

Contudo, essa subordinação nunca foi aceita por todas, o que originou diversos confrontos denominados de "Ondas do Feminismo", que foram responsáveis por originar diversos documentos nacionais e internacionais, alguns com valor jurídico e outros sem, mas todos colaboraram de alguma forma para a mudança da estrutura 
hierárquica existente na sociedade (SILVA; SEABRA; SOARES JÚNIOR, 2016, p. 302).

A busca pela ruptura desse estado de submissão imposto às mulheres de deu por meio do feminismo, que se dividiu em três ondas principais (SILVA; SEABRA; SOARES JÚNIOR, 2016, p. 302):

Primeira onda: com início no final do século XVIII, teve inspiração nos ideais de liberdade, igualdade e fraternidade na Revolução francesa, apresentando como principal conquista do direito ao voto. Essa onda foi responsável por questionar a estrutura patriarcal e sexista da sociedade, bem como por iniciar a luta pela igualdade e maior participação das mulheres no espaço público.

Segunda onda: surgiu na metade do século XX, momento em que, apesar de ter conquistado o direito ao voto, as mulheres ainda buscavam o fim da desigualdade e discriminação de gêneros, bem como maior participação na política. Nessa época, no Brasil, a mulher ainda era considerada incapaz de realizar alguns atos na vida civil e até precisava de autorização para trabalhar ou receber herança, por exemplo $^{4}$. Seu fím é datado em 1988, momento em que a Constituição Federal formalmente reconheceu do direito à igualdade.

(iii) Terceira onda: Iniciou-se em 1990, sendo composta pelos desdobramentos do feminismo, que envolvem os direitos sexuais e reprodutivos.

O feminismo, até os dias de hoje, luta contra essa desigualdade de gênero que ainda é alarmante na sociedade. Segundo Judith Butler (1990), frente ao cenário patriarcal, é necessário lutar em prol da desconstrução dessa visão de inferioridade das mulheres em relação aos homens. De acordo com a autora:

\begin{abstract}
Para a teoria feminista, o desenvolvimento de uma linguagem capaz de representá-las completa ou adequadamente pareceu necessário, a fim de promover a visibilidade política das mulheres. Isso parecia obviamente importante, considerando a condição cultural difusa na qual a vida das mulheres era mal representada ou simplesmente não representada. Recentemente, essa concepção dominante da relação entre teoria feminista e política passou a ser questionada a partir do interior do discurso feminista.
\end{abstract}

${ }^{4}$ Por determinação legal, exigia-se que as profissões deveriam ser exercidas com a autorização dos maridos. E até a atual Constituição (CRFB/88), a mulher casada necessitava de autorização do marido para trabalhar, embora tal autorização fosse presumida. Nesse sentido, são os trechos destacados de legislações brasileiras dos séculos XIX e XX que evidenciavam a maior participação da mulher no cenário público além do privado (SILVA; SEABRA; SOARES JÚNIOR, 2016, p. 302). 
O próprio sujeito das mulheres não é mais compreendido em termos estáveis ou permanente (...) (BUTLER, 2013, p. 18).

Homens e mulheres são atingidos pelos reflexos da desigualdade de gêneros em que estão inseridos. Isto ocorre porque essa ideia de homem como gênero dominante é uma visão que foi construída não apenas por homens, como também pelas mulheres que cresceram nessa realidade e incorporaram a posição de sexo frágil, submisso e dependente da figura masculina (SILVA; ALBERTON, 2019).

Com base nisso, a sociedade patriarcal e essencialmente machista foi se construindo ao longo dos últimos séculos, o que pode levar o mesmo lapso temporal para ser modificado ou desconstruído, motivo pelo qual há séculos as mulheres vêm tentando eliminar a desigualdade e discriminação de gênero que ainda se apresenta muito enraizada no seio social

Nesse diapasão, debates feministas afirmam que a desigualdade de gêneros gera violência contra a mulher pelo simples fato de ela ser mulher. A sensação de superioridade que o homem tem o faz sentir no poder de enquadrar a mulher às suas regras e à posição de submissão, de modo que "a partir do conceito de gênero que se desenvolve o conceito de violência de gênero" (CAMPOS, 2013).

Entretanto, a simples diferenciação biológica de sexos não é suficiente para definir as questões de gênero relacionadas ao feminicídio. Estas, na verdade, são complexas e envolvem questões históricas, sociais e culturais, que ultrapassam meras distinções anatômicas existentes entre homens e mulheres (SILVA; ALBERTON, 2019).

O feminicídio, então, é consequência de uma sociedade essencialmente machista, na qual o homem acredita ser superior às pessoas do sexo oposto. Nesse meio, a sensação de superioridade desenvolve o sentimento de posse e dominação, onde ele atrai a vítima para uma verdadeira armadilha.

O homem faz a mulher acreditar que é incapaz e vulnerável e que precisa de seu apoio e proteção. Com isso, a induz a vítima a se prostrar aos seus desejos, ofertando em troca a suposta "proteção", que pode ser social e/ou econômica. No final, a mulher se percebe em uma prisão, sujeitada aos mais diversos tipos de abusos, que pode desembocar na forma mais grave de violência, a morte (SILVA; ALBERTON, 2019). 
Infelizmente, casos de violência contra a mulher são diariamente noticiados, seja por questão passional ou de gênero. Assim, é fácil perceber a importância do estudo e discussão desta temática não só para o Brasil, mas para o mundo todo.

Nessa luta contra a violência contra as mulheres, os movimentos feministas têm sido um dos maiores colaboradores, exigindo a elaboração e efetivação de políticas públicas, bem como da disponibilização de mecanismos de proteção para essas mulheres.

A criação do tipo penal do feminicídio é, portanto, considerado um marco político e acadêmico para o feminismo, pois conferiu visibilidade para as crescentes mortes de pessoas do sexo feminino em razão do gênero, mormente porque muitos casos ocorrem dentro do ambiente familiar e são praticados por pessoas íntimas das vítimas, o que dificulta o controle e/ou contenção.

\section{Casos que marcaram o percurso histórico do feminicídio}

Diversos fatos históricos trouxeram visibilidade para a violência de gênero, tornando-a foco de preocupação ao redor do mundo. Dois deles poucos comentados como, em 1989, o Massacre da Escola Politécnica da Universidade de Montreal, no Canadá e o grande quantitativo de homicídios de mulheres em Ciudad Juárez, no México.

No Massacre da Escola Politécnica da Universidade de Montreal, quatorze mulheres foram assassinadas e outras treze pessoas ficaram feridas, dentre as quais estavam nove mulheres (SILVA; ALBERTON, 2019). O autor do crime não havia conseguido uma vaga na referida instituição de ensino e se matou logo após o massacre, deixando uma carta informando que havia realizado o ato porque as mulheres estavam tomando cada vez mais o lugar dos homens na sociedade (SILVA, 2015).

Como é possível se verificar, muitos homens não sabiam - e ainda não sabem - lidar com ascensão social da mulher, não aceitando que elas estão cada vez mais próximas deles, seja em quesito social, político, acadêmico, profissional ou doméstico (PASINATO, 2011). 
Em relação à elevada taxa de mortes de mulheres em Cidade de Juárez, no México, esta foi denunciada por Maria Marcela Lagarde y de los Rios, antropóloga e pesquisadora, ao comentar que desde 1990 o número de homicídios e desaparecimento de mulheres têm aumentado e que isto estava sendo objeto de grade descaso e omissão estatal.

A autora também era deputada de seu país, e resolveu criar uma comissão para analisar as mortes das mulheres com base em dados oficiais, demonstrando que a violência contra as mulheres era algo que alcançava dimensão nacional, não se restringindo a Cidade de Juarez. Além disso, seus estudos revelaram as principais características das vítimas e dos locais com maior índice de criminalidade ${ }^{5}$.

Um evento que trouxe à baila a temática da violência contra as mulheres no Brasil foi o caso da jornalista Sandra Gomide que, em 2000, foi assassinada pelo seu ex-namorado e também jornalista Antônio Marcos Pimenta Neves ${ }^{6}$. Esse crime teve grande repercussão na mídia, pois o autor do crime era jornalista renomado perante a sociedade.

Sandra Gomide tinha 33 anos, enquanto seu ex-namorado tinha 63 anos, no momento da ocorrência do delito. Eles trabalharam na mesma empresa, o Jornal O’Estado de São Paulo, até julho de 2000, quando eles terminaram o namoro e Pimenta Neves demitiu Sandra (VILAGARDA, 2013).

A partir disso, Sandra foi vítima de perseguição, ameaças e difamação, chegando até a prestar uma denúncia formal e a contratar um segurança particular. No entanto, tudo isso não foi suficiente, pois o seu ex-namorado a esperou em um local que ela costumava frequentar e desferiu três tiros em suas costas (VILAGARDA, 2013).

Ao final, o Antônio Marcos Pimenta Neves confessou o crime, foi condenado apenas em 2006 a 19 anos de prisão, que posteriormente foi reduzida para 15 anos e somente começou a cumprir a pena 11 anos depois da prática do crime.

A morte de Sandra Gomide demonstrou que a violência contra as mulheres, independente de cor, nível de educação ou classe social, pois todas estão inseridas em

\footnotetext{
${ }^{5}$ Os estudos de Lagarde foi muito relevante, pois trouxe atenção para a temática ao redor do mundo (LAGARDE Y DE LOS RIOS, 2008).

${ }^{6}$ Antônio Marcos Pimenta Neves é um ex-analista da área de Economia e Finanças e ex-diretor de Redação do jornal O Estado de S. Paulo. Tornou-se conhecido por ter assassinado, em 2000, a namorada jornalista Sandra Gomide, em um haras em Ibiúna, interior de São Paulo (Fonte: https://pt.wikipedia.org/wiki/Pimenta_Neves).
} 
realidade social de desigualdade de gêneros e de dominação masculina, o que as colocam em constante risco de sofrerem algum tipo de violência.

Em 2006 houve a edição da Lei Maria da Penha, que teve o escopo de criar instrumentos capazes de coibir, prevenir e até eliminar a violência doméstica e intrafamiliar contra a mulher, visando preservar sua integridade física, psíquica, moral e patrimonial da vítima.

No entanto, o surgimento da referida lei apenas surtiu um efeito modesto na contenção de violência contra as mulheres, o que exigiu do poder estatal novas medidas em prol da contenção dos crimes contra as mulheres.

Com isso, houve a edição da Lei do Feminicídio, que alterou o Código Penal, incluindo o feminicídio nas circunstâncias qualificadoras do homicídio, bem como inserindo-o no rol de crimes hediondos, com o objetivo de endurecer a penalidade para este tipo penal e, assim, diminuir os casos de violência de gênero.

\section{Debate jurídico e justificativas para a edição da lei}

A criação da Lei do Feminicídio, do ponto de vista jurídico, foi uma iniciativa legislativa acompanhadas de críticas e debates calorosos, onde foram apresentados tanto argumentos a favor da lei, quando contrários à sua publicação.

Dentre os argumentos contrários a edição da lei, nenhum teve a coragem de alegar a inexistência de dominação, discriminação, sujeição e violência constante. Os posicionamentos contrários arguiram que asseverar a penalidade para o homicídio de mulheres fragilizaria a luta pela igualdade de gêneros, pois estaria estabelecendo uma diferenciação no trato do homicídio praticado entre homens e mulheres (SOUSA, 2016). Na argumentação de argumento de Yarochewsky (2014):

\footnotetext{
"Ao tratar de forma diferenciada a mulher - punindo com mais severidade o homicídio praticado contra a mesma -, numa clara demonstração de discriminação em que a mulher é, em uma visão paternalista, disposta como o sexo frágil, o projeto, também, viola o princípio constitucional da igualdade entre pessoas do mesmo sexo. [...] Ao tratar o homicídio perpetrado contra mulher (feminicídio) mais severamente do que o cometido contra o homem, o projeto está dizendo que a vida da mulher vale mais que a do homem. Está tratando bens jurídicos idênticos (vida humana) de maneira desigual. Isto, além de violar a Constituição, pode se transformar em perigosa e odiosa forma de discriminação. [...].
} 
Nesse sentido, nota-se que havia argumentos bem distintos, pois, de um lado se defendia a igualdade de direitos e a isonomia no tratamento dos homens e mulheres, enquanto, por outro, entendia-se acerca da necessidade da modificação dos mecanismos de julgamento e punição como forma de oportunizar a resolução do conflito (SOUSA, 2016).

$\mathrm{Na}$ verdade, é possível argumentar que a criação de mecanismos judiciais de punição não é capaz de fazer a população assimilar valores socais essenciais para a modificação da realidade sexista que se vive na atualidade. Entretanto, é descabida a falsa defesa de igualdade formal de gêneros, uma vez que a desigualdade está enraizada em nossa sociedade, se apresentando nas mais diversas formas de discriminação contra a mulher.

Ademais, o feminicídio não ocorre em um contexto de competição de interesses ou poder, mas sim em uma situação em que a mulher é tão subvalorizada, que ela é assassinada devido ao menosprezo e discriminação por ela ser sexo feminino. Segundo Mariana Paes:

(...) não se trata de considerar a mulher como «sexo frágil», mas de reconhecer que mulheres e homens vivenciam, na vida privada, no âmbito doméstico e nas relações afetivas, situações de desigualdade que propiciam o uso da violência contra as mulheres. (...) Reconhecer a condição hipossuficiente da mulher vítima de violência doméstica e/ou familiar não implica invalidar sua capacidade de reger a própria vida e administrar os próprios conflitos. Trata-se de garantir a intervenção estatal positiva, voltada à sua proteção e não à sua tutela (PAES, 2015).

Sendo assim, resta claro que a edição da lei teve o objetivo de reduzir os crimes contra as mulheres em razão do gênero, com a modificação do julgamento e aumento das penas para este tipo penal, isto porque a punição, ainda que individual, serve de exemplo e é capaz de dissuadir condutas e comportamentos, inibindo novas práticas delituosas. Mas também tem o poder simbólico de criar consciência na sociedade, incluídos aqui os envolvidos no processo, autoridades e cidadãos, sobre a morte letal de mulheres e como isso afeta a sociedade. 


\section{Considerações Finais}

A violência contra as mulheres não é algo recente, mormente porque está estritamente relacionado com as raízes patriarcas nas quais repousa a sociedade brasileira. Por causa disso, a cultura do país é extremamente machista e desigual, criando um ambiente de vulnerabilidade para pessoas do sexo feminino.

O feminicídio ocorre, em regra, no espaça familiar, local onde a mulher deveria se sentir - e ter - mais segura. No entanto, ela encontra dentro de sua própria casa, um homem que após uma sequência de atos de agressão (física, psicológica, moral ou patrimonial) chega as etapas finais da violência contra a mulher, o assassinato.

Este tipo penal é definido como sendo o homicídio de uma mulher devido a condição do seu gênero, ou seja, pelo simples fato de ela ser do sexo feminino. É considerado um crime de ódio, que envolve o menosprezo e desprezo do homem em relação as mulheres.

As primeiras referências terminológicas ao feminicídio, o assemelhavam ao genocídio de mulheres, pois assemelhava esta situação a processos de exterminação seletiva de certos grupos de seres humanos que outrora já existiram. A partir disso, o conceito foi se modificando aos poucos até chegar ao que está descrito no Código Penal: "homicídio cometido contra a mulher por razões da condição de sexo feminino".

Apesar da sociedade ser baseada em ditames patriarcais, que pregaram a superioridade masculina e a submissão e sujeição do sexo feminino, nem todas as mulheres aceitavam essa situação e foi assim que se deram os movimentos feministas em prol da igualdade entre homens e mulheres.

O feminismo foi um dos grandes colaboradores para a edição da Lei do Feminicídio, pois, desde sempre, lutam contra a opressão masculina, bem como tentar acabar com essa ilusão de que os homens têm o domínio e poder sobre as mulheres, pois isso acarreta muitas mortes em razão do gênero.

No decorrer deste estudo, comentamos alguns casos que despertaram nas sociedades o debate acerca deste tipo de violência contra as mulheres, bem como 
alertaram para o crescimento constante do quantitativo de vítimas e urgente necessidade da interferência do poder público para fins de controle da situação.

Com isso, após muito debate, houve edição da referida lei, que tornou o feminicídio circunstância qualificadora do homicídio, bem como o colocou no rol de crimes hediondos, o que aumentou sua pena, bem como modificou sua forma de julgamento.

A violência contra a mulher não é algo recente e existe em todo o mundo, pois a maioria das sociedades foram construídas sob os pilares do patriarcalismo, que desenvolveu uma desigualdade desproporcional entre homens e mulheres, o que desenvolve nos homens um sentimento de superioridade e "direito" sobre a vida das mulheres.

A criação da lei do feminicídio foi uma verdadeira conquista, com a qual se espera que ocorra uma modificação da mentalidade da sociedade, bem como dos atores jurídicos envolvidos no processo, construindo novos valores e posicionamentos nesse campo de atuação e na luta contra a violência contra as mulheres. Outrossim, espera-se que o aumento da pena seja capaz de ensinar na dimensão pedagógicapunitivo, assim como agir simbolicamente como um instrumento conscientizador acerca da violência letal contra as mulheres e como isso afeta toda a sociedade.

\section{Referências}

BRASIL. Decreto-Lei $\mathrm{n}^{\mathrm{o}}$ 2.848/40. Código Penal. Disponível em: $<$ http://www.planalto.gov.br/ccivil_03/decreto-lei/del2848compilado.htm>. Acesso em: $10 / 05 / 2021$.

BRASIL. Lei $\mathrm{n}^{\circ} 11.340 / 06$. Lei Maria da Penha. Cria mecanismos para coibir a violência doméstica e familiar contra a mulher, nos termos do $\S 8^{\circ}$ do art. 226 da Constituição Federal, da Convenção sobre a Eliminação de Todas as Formas de Discriminação contra as Mulheres e da Convenção Interamericana para Prevenir, Punir e Erradicar a Violência contra a Mulher; dispõe sobre a criação dos Juizados de Violência Doméstica e Familiar contra a Mulher; altera o Código de Processo Penal, o Código Penal e a Lei de Execução Penal; e dá outras providências. Disponível em: < http://www.planalto.gov.br/ccivil_03/_ato2004-2006/2006/lei/111340.htm>. Acesso em: 10/05/2021.

BRASIL. Lei ${ }^{\circ}$ 11.104/15. Altera o art. 121 do Decreto-Lei $n^{\circ} 2.848$, de 7 de dezembro de 1940 Código Penal, para prever o feminicídio como circunstância qualificadora do crime de homicídio, 
e o art. $1^{\circ}$ da Lei $n^{\circ} 8.072$, de 25 de julho de 1990, para incluir o feminicídio no rol dos crimes hediondos. Disponível em: $<$ http://www.planalto.gov.br/ccivil_03/_ato20152018/2015/lei/113104.htm>. Acesso em: 10/05/2021.

BUTLER, Judith. 1990. Gender Trouble: Feminism and the Subversion of Identity. Nova Iorque: Routledge

CAMPOS, Carmen Hein de. Lei Maria da Penha: desafios para a integração de novos sujeitos de direitos. In: Estudos feministas e de gênero: articulações e perspectivas. p. 490.Disponível em http://www.compromissoeatitude.org.br/wp-content/uploads/2014/02/1_8_tensoes-atuais.pdf.

Acesso em 11/05/2021.

ESPÓSITO, Carlos. Marcela Lagarde y la invención de la categoría 'feminicidio'. Blog Aquiescencia. 2011. Disponível em: <http://aquiescencia.net/2011/ 05/02/marcela-lagarde-y-lainvencion-de-la-categoria-feminicidio $>$. Acesso em 11/05/2021.

FERNANDES, Valéria Diez Scarance. Lei Maria da Penha: o processo penal no caminho da efetividade, abordagem jurídica e multidisciplinar (inclui lei de feminicídio). Atlas: São Paulo, 2015.

GEBRIM, Luciana Maibashi; BORGES, Paulo Cesar Correa. Violência de Gênero: Tipificar ou não o femicídio/feminicídio? . 2014.2 Disponível em: $<$ https://www12.senado.leg.br/ril/edicoes/51/202/ril_v51_n202_p59.pdf $>$. Acesso em: $10 / 05 / 2021$

JESUS, Damásio de. Violência contra a mulher: aspectos criminais da Lei n. 11.340/2006. 2 Ed. São Paulo: Saraiva, 2015.

LAGARDE, Marcela y de los Ríos. Del femicidio al feminicidio. Desde el jardín de Freud Revista de Psiconálisis. Bogotá, n. 6, p. 216-225, 2006. Disponível em: < https://revistas.unal.edu.co/index. php/jardin/article/view/8343/ 8987 >. Acesso em 10/05/2021.

LOUREIRO, Ythalo Frota. Conceito e Natureza Jurídica do Feminicídio. Revista Acadêmica Escola Superior do Ministério Público do Ceará. 2017. Disponível em: < http://www.mpce.mp.br/wp-content/uploads/2017/08/8-Conceito-e-Natureza-Jur\%C3\%ADdicado-Feminic\%C3\%ADdio.pdf $>$. Acesso em 10/05/2021.

OLIVEIRA, Clara Flores Seixas de. Do pensamento feminista ao código penal: o processo de criação da lei do feminicídio no brasil. Universidade Federal da Bahia. Faculdade de Filosofia e Ciências Humanas. Programa de Pós-graduação em Ciências sociais. Dissertação (Mestrado). Salvador, 2017.2 Disponível em: https://ppgcs.ufba.br/sites/ppgcs.ufba.br/files/dissertacao_clara.pdf $>$. Acesso em: 11/05/2021.

OLIVEIRA, Patrícia Peres de et al. Mulheres vítimas de violência doméstica: uma abordagem fenomenológica. Texto contexto - enferm, vol.24, n.1, pp.196-203, 2015.

PAES, Mariana Armond Dias. 2015. «Inclusão do feminicídio no Código Penal é uma questão de igualdade e gênero», Blog Consultor Jurídico, 10.01.2015. Disponível em: < http://www.conjur.com.br/2015-jan-10/mariana-paes-feminicidio-questaoigualdadegenero\#author>. Acesso em: 11/05/2021.

RODRIGUES, Gabriella Barrozo Garcia; MOROTTI, Juliana Midori. Feminicídio: uma análise histórica, sociocultural e sociojurídica da violência contra as mulheres no século xxi. XIV 
Semana Acadêmica de História: Diversidade, Ensino e Políticas Públicas no século XXI, UNIOESTE, 2017.

RUSSEL, Diana E. H., e CAPUTI, Jane. "Femicide": Speaking the Unspeakable. Revista Ms 1. n. 2, 1990. Disponível em: < http://www.unc.edu/ kleinman/handouts/ Femicide.pdf $>$. Acesso em 24 out. 2017.

SILVA, Cristian Kiefer; SEABRA, Débora Totini; SOARES JÚNIOR, Luiz Antônio. Feminismo, violência e poder: uma análise histórico-jurídica da Trajetória e dos documentos que culminaram na lei maria da Penha e no feminicídio. Cadernos do Programa de Pós-graduação em Direito PPGDir/UFRGS, Porto Alegre, v. 11, n.3, p. 301-334, 2016.

SILVA, Maria Eduarda Praxedes. O feminicídio como circunstância qualificadora do homicídio no sistema penal brasileiro: o direito penal pode ser instrumento no combate à violência de gênero? 2015. Disponível em: <https://editora.pucrs.br/anais/congresso-decriminologia/assets/2015/56.pdf>. Acesso em? 12/05/2021.

SILVA, Maria Isabele da; ALBERTON, Mário Henrique. A lei do feminicídio 13.104/2015 e seus impactos no estado do Paraná. Actio Revista de Estudos Jurídicos, N. 29, v. 2 - Julh./Dez. 2019.

SOUSA, Tania Teixeira Laky de. Feminicídio: uma leitura a partir da perspectiva feminista. Ex æquo, n. ${ }^{\circ}$ 34, pp. 13-29, 2016.

VILARDAGA, Vicente. À Queima-Roupa: O caso Pimenta Neves. 1 Ed. São Paulo: Leya, 2013.

YAROCHEWSKY, Leonardo Isaac. 2014. Feminicídio é um retrocesso na busca pela igualdade e no combate à discriminação. Blog Consultor Jurídico, 26.12.2014 Disponível em: < http://www.conjur.com.br/2014-dez-26/leonardo-yarochewsky-feminicidioretrocesso-buscaigualdade?utm_source $=$ dlvr.it\&utm_medium=facebook\#author:> Acesso em: Acesso em: $11 / 05 / 2021$.

\section{How to cite this article (APA format):}

Farias, A.A.F. (2021). Historical approach on the creation of the Femicide Law in Brazil. Am. In. Mult. J., Oct. (11) 6, 60-74.

Received: 10/19/2021

Accepted: 10/28/2021

Published: 10/31/2021 